\title{
Structural identification of Humber Bridge for performance prognosis
}

\author{
R Rahbari ${ }^{1}, \mathrm{~J} \mathrm{Niu}^{2}$, JMW Brownjohn ${ }^{2}, \mathrm{~K}-\mathrm{Y} \mathrm{Koo}^{2}$ \\ ${ }^{1}$ Department of Civil Engineering, University of Sheffield, Sheffield, United Kingdom \\ ${ }^{2}$ School of Civil Engineering, Southeast University, Nanjing, China \\ ${ }^{3}$ College of Engineering, Mathematics and Physical Science, University of Exeter
}

\begin{abstract}
Structural identification or St-Id is 'the parametric correlation of structural response characteristics predicted by a mathematical model with analogous characteristics derived from experimental measurements'.
\end{abstract}

This paper described a St-Id exercise on Humber Bridge that adopted a novel two-stage approach to first calibrate and then validate a mathematical model. This model was then used to predict effects of wind and temperature loads on global static deformation that would be practically impossible to observe.

The first stage of the process was an ambient vibration survey in 2008 that used operational modal analysis to estimate a set of modes classified as vertical, torsional or lateral. In the more recent second stage a finite element model (FEM) was developed with an appropriate level of refinement to provide a corresponding set of modal properties. A series of manual adjustments to modal parameters such as cable tension and bearing stiffness resulted in a FEM that produced excellent correspondence for vertical and torsional modes, along with correspondence for the lower frequency lateral modes.

In the third stage traffic, wind and temperature data along with deformation measurements from a sparse structural health monitoring system installed in 2011 were compared with equivalent predictions from the partially validated FEM.

The match of static response between FEM and SHM data proved good enough for the FEM to be used to predict the un-measurable global deformed shape of the bridge due to vehicle and temperature effects but the FEM had limited capability to reproduce static effects of wind. In addition the FEM was used to show internal forces due to a heavy vehicle to to estimate the worst-case bearing movements under extreme combinations of wind, traffic and temperature loads.

The paper shows that in this case, but limitations, such a two-stage FEM calibration/validation process can be an effective tool for performance prognosis.

\section{Keywords}

Suspension bridge structural identification model updating modal test temperature vehicle wind static 


\section{Introduction}

Trouble-free operation of suspension bridges requires that the design caters for the full range of static and dynamic loads and their combinations and that predicted performance in terms of internal forces and deformations is within tolerable limits.

Each suspension bridge is unique so that unlike mass-produced aircraft or automobiles there are no opportunities to test designs at full-scale before construction. Hence performance is simulated with numerical or finite element models and wind tunnel tests on scaled physical modes. Reliability of such simulations depends on both a good understanding of the loading and the ability of the model to represent the structural behavior. Deficiencies in either can result in expensive, inconvenient or even catastrophic surprises.

By the time 'out of bounds' performance is observed on the as-built structure the only option is a costly retrofit or usage restriction. For example a number of North American bridges (Abdel-Ghaffar \& Scanlan 1985; Kumarasena et al. 1989) have had to be retrofitted due to lively in-wind performance while for Great Belt Bridge the fix was by aerodynamic modifications through wind vanes (Larsen et al. 2000). The other major effect that may be unforeseen is the effect of extreme combinations of thermal, traffic and wind movement on excursions at interfaces among spans, towers and abutments. There have been several surprises at the scale of these movements that have led to premature and costly retrofits.

Hence for an existing structure there are strong motivations to develop a good understanding of the structural behavior and hence the impact of unusual or increased loads. A finite element model (FEM) calibrated or updated (Friswell \& Mottershead 1995) using modal properties identified through system identification provides are the best tool for simulating such scenarios. It also offers the capability for full understanding and physical interpretation of the causes and effects of the various loading regimes as a form of performance diagnosis.

Models updated based on modal tests should however be used with caution (Brown \& Milne, 1985). In principle such models should not be relied on to do more than reproduce the modal properties used to validate them (a form of interpolation) whereas to go beyond those measurements is a risky process akin to extrapolation. This does not always work; one example is the structurally complex Tamar Bridge where a formally updated FE model was unable to reproduce observed effects on modal properties of significant variations in traffic load (Westgate et al., 2015).

The aim of this paper is to explore the next step in producing a reliable, updated FE model that justifies faith in extrapolation. Hence in this study, a FEM of Humber Bridge has been developed then calibrated against results of a system identification process using operational modal analysis of dynamic response to ambient dynamic loads measured over a few days of normal operation. In the next step the calibrated FEM has been used to estimate the static response of the bridge to wind, vehicle and thermal loads and to compare the predictions with observations from a structural health monitoring (SHM) system operating on the bridge. This whole process encapsulates the definition of structural identification (St-Id) as 'the parametric correlation of structural response characteristics predicted by a mathematical model with analogous characteristics derived from experimental measurements' (Catbas et al. 2013).

Having established that the FEM predicts observed static response reasonably well, the final step was to use the model to predict some results that could not be observed experimentally. These results include global deformations due to wind loads, but more importantly effects of worst-case combinations of extreme loads and even internal forces.

\section{Humber bridge: Structural details and previous studies}

Humber Bridge (Figure 1) was opened in July 1981 and has a main span of $1410 \mathrm{~m}$ with side spans of $280 \mathrm{~m}$ and $530 \mathrm{~m}$. It links the small towns of Hessle (north) and Barton (south), with the bridge longitudinal axis aligned in an approximate north-south direction. Like its predecessors Severn and Bosporus, Humber has aerodynamic steel box girders and inclined hangers. The spans comprise a total of 124 prefabricated units typically $18.1 \mathrm{~m}$ long and $4.5 \mathrm{~m}$ deep. These are $28.5 \mathrm{~m}$ wide and 
include two $3 \mathrm{~m}$ walkways and orthotropic deck plates on which road surfacing is applied. The slipformed reinforced concrete towers rise $155.5 \mathrm{~m}$ above the caisson foundations and carry the two main cables with nominal sag of $115.5 \mathrm{~m}$. The bridge is exposed to prevailing south-westerly cyclonic winds that can reach hurricane force (exceeding $32.7 \mathrm{~m} / \mathrm{sec}$ ), with atmospheric temperatures ranging from $-10^{\circ} \mathrm{C}$ to $30^{\circ} \mathrm{C}$.
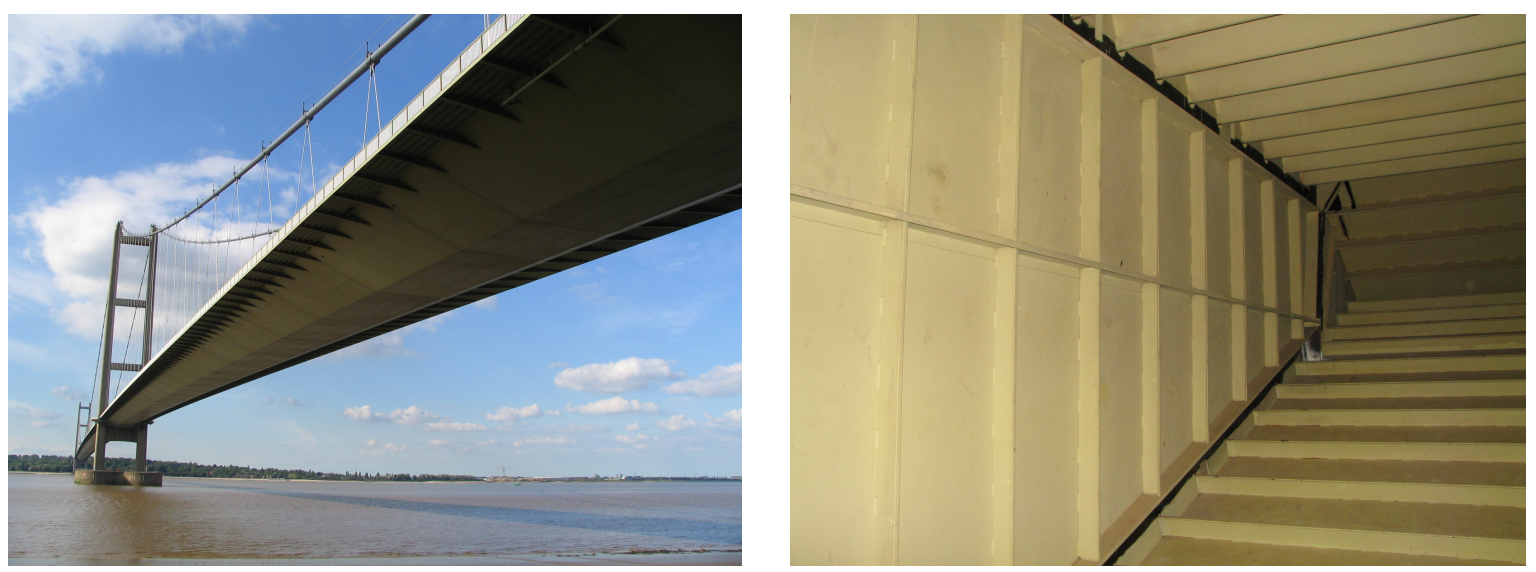

Figure 1: Views of Humber Bridge. Left: View from Barton anchorage, Right: box deck interior.

Humber has been the subject of several academic investigations focusing on dynamic performance. Ambient vibration surveys were carried out in 1985 by University of Bristol and Building Research Establishment (BRE), (Brownjohn et al. 1987; Littler 1992), BRE again in 1988 (Littler \& Woods 1989) and most recently in 2008 by University of Sheffield and helpers (Brownjohn et al. 2010).

Observations from the 1985 modal test and the linked finite element analysis (Brownjohnet al., 1987) suggested that the pairs of A-frame rocker bearings at each span end, which were designed to prevent translation in vertical and lateral directions but to allow free movement along the bridge longitudinal axis were not functioning quite as expected. The clearest effect of this was the appearance of the first anti-symmetric vertical vibration mode at a higher frequency than that of the first symmetric mode, whereas for a completely free sliding condition it would be the first mode to appear.

Separate from the modal investigations and potentially having greater impact, several campaigns have deployed state of the art technology for tracking static deformation. In particular, In the period 1989 to 1991 a campaign of measurements (Brownjohn et al. 1994) led by Politecnico di Milano supported in-wind performance studies of a design for the proposed Stretto di Messina crossing (Brancaleone \& Diana, 1993). The measurement campaigns included novel optical systems for measuring displacement. The exercise also provided data for identification of aero-elastic flutter derivatives at full scale (Diana et al. 1992). There has also been a brief evaluation of GPS technology by Nottingham University (Ashkenazi \& Roberts 1997).

Following the 2008 modal test, a monitoring system comprising GPS antennae, lasers, a tilt-meter, accelerometers, thermistors and an anemometer was installed on the bridge and has operated since early 2011 (Brownjohn et al). With the more sophisticated technology compared to the 1989-1991 campaign, the deformation data available from this system are not only richer but cover a longer period. Hence they represent more extreme conditions and have provided fresh insights into the performance of the bridge. In particular, while the early system predated the era of 'structural health monitoring', the present system is designed to provide automatic data processing, data visualisation and capability for online anomaly detection and load identification. To provide additional capability, a numerical model of the bridge has been developed, for performance interpretation and simulation, providing an effective combination for structural health monitoring of the bridge.

As well as two-dimensional finite element analysis by Freeman Fox \& Partners (designers), several numerical models of Humber Bridge have been developed e.g. (Dumanoglu \& Severn 1987; Karuna 2002; Hornby et al. 2012). The former example provided an opportunity to calibrate novel finite 
element modeling techniques for suspension bridges to be applied to seismic response analysis of the two bridges crossing the Bosporus in Istanbul.

\section{Structural health moniutoring, system identification and structural identification (St-Id)}

Structural health monitoring offers two approaches for evaluating the present performance (diagnosis) and predicting future performance (prognosis) of structures. One is based on data-driven models (Worden \& Manson 2007) that are effectively curve-fits to historic load and performance data. The second is the physics-based approach (Farrar \& Lieven 2007) where a finite element model (FEM) is calibrated or adjusted to fit data from measurements of dynamic and/or static response. The whole process of creating and calibrating a physics-based model for performance diagnosis fits the definition of St-Id (Catbas et al. 2013) and usually includes system identification to extract modal properties from dynamic response measurements obtained in a modal test.

Both data-driven and physics-based approaches have been applied to the shorter Tamar Bridge (Cross et al. 2013). This bridge features a traditional truss girder, with added complexity of retrofitted cantilever lanes and additional stay cables. That exercise demonstrated the limitations of applying a model validated using only modal test data, since using that model (in effect extrapolating) to reproduce the effects of temperature and traffic variations on natural frequencies proved challenging (Westgate et al. 2015). The aim here is to demonstrate the power of the physics-based approaches with additional validation from static response data for what is in fact a simpler structure.

\section{8 modal test and long term monitoring}

In July 2008 a team of researchers from University of Sheffield (UK), City University of Hong Kong and Faculty of Engineering, University of Porto used a sequence of 33 one-hour measurements over five days to map out mode shapes and identify natural frequencies and damping ratios for Humber Bridge. The exercise and the operational modal analysis (OMA) applied for system identification of the modal properties are fully described elsewhere e.g. (Brownjohn et al. 2010).

During the campaign winds were moderate temperature ranges small. Ten autonomous tri-axial accelerometers measured at 76 positions each with a pair of recorder on either side of the bridge, a total of $76 \times 6$ degrees of freedom, not all independent. The recorders were synchronized by GPS antennae and used the reference/rover technique to provide for high spatial resolution of mode shapes.

The long term monitoring system was installed as part of the same research project. The system is illustrated in Figure 2 and comprises three GPS antennae (one base station and two rovers, for real time kinematic operation), three servo accelerometers and one biaxial inclinometer at midspan, and four extensometers in pairs at each end of the main span. The rationale for using only three accelerometers is that having the full set of mode shapes from the modal test, the total dynamic response at any point in the structure can be obtained by modal superposition. There are also temperature and weather sensors at various locations. 


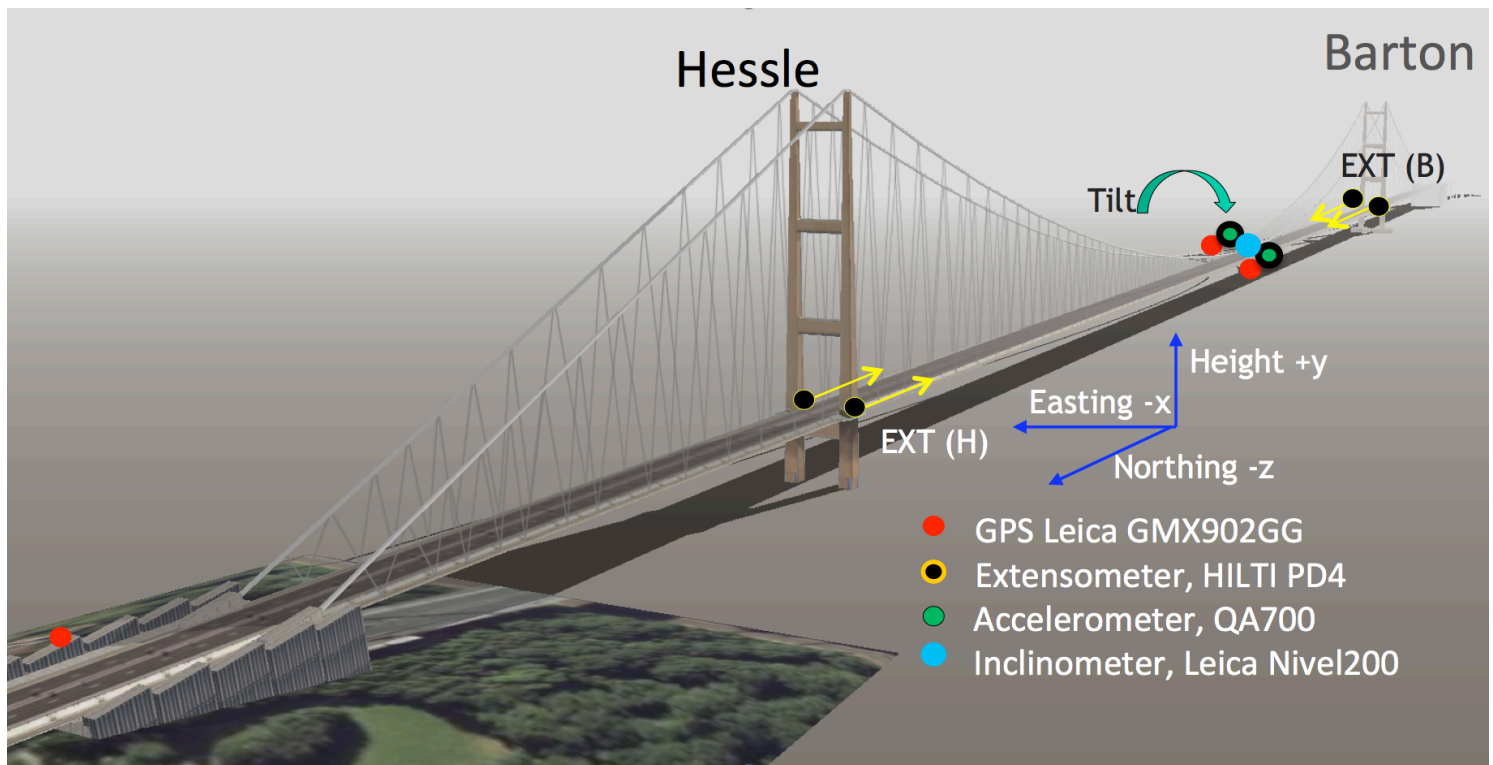

Figure 2: Humber Bridge instrumentation and directional conventions

The acceleration data are useful for tracking modal parameters and response levels in lowest few modes that are susceptible to buffeting and aero-elastic effects. However it is the quasi-static deformation observed through the GPS, extensometers and DC component of lateral acceleration (interpreted as rotation) that is relevant here and which is usually most important to bridge operators.

The modal survey provided the means to validate and update the FEM described next, while the monitoring system provided deformation signatures for further validation of the updated FEM.

\section{Developing the finite element model}

In order to provide a reliable physics-based simulator to rationalize observations from the monitoring, a detailed FEM of the bridge was developed. A FEM developed in previous studies (Dumanoglu \& Severn 1987) using modified SAPIV software (Bathe et al. 1974) assisted development of a more elaborate ANSYS model. Main components of the model would be two twin-pylon towers, the bridge deck (main and two unequal side spans), main cables, bearings and expansion joints.

\subsection{Box girders}

Model creation began with developing an appopriate representation of the box girder, shown in Figure 3 with typical dimentions and one of the four equi-spaced stiffening bulkheads. A high resolution model with all features of the stiffeners would not necessarily justify the time and computing resources required, so an equivalent section model was created, with appropriate adjustment of thickness and density to represent the stiffening details. Details such as overlap joints and fatigue reducing holes in deck longitudinal stiffeners visible in Figure 1 were ignored to simplify the model.

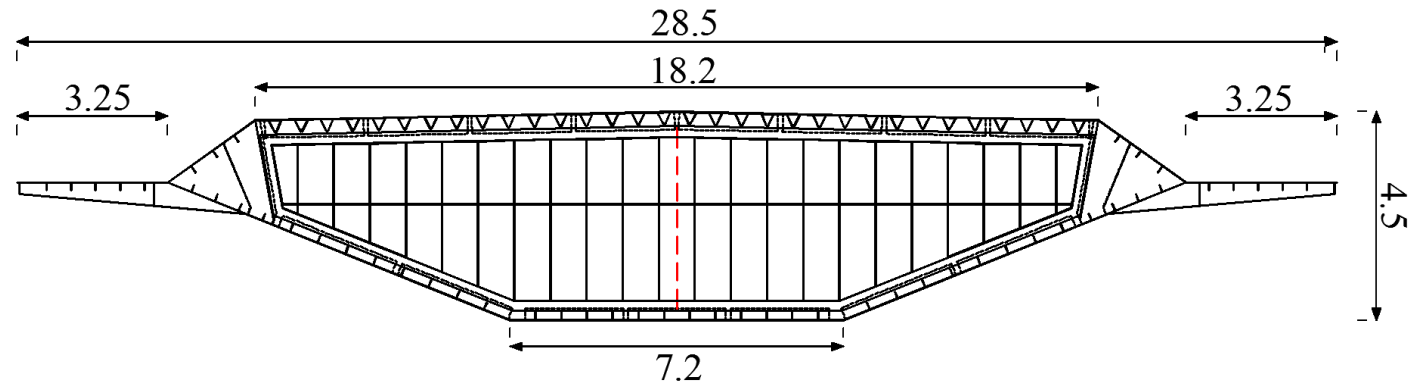

Figure 3: Deck Section. Dimensions in $\mathrm{m}$. 


\subsection{Towers and cables}

Hollow reinforced concrete tower columns taper from $30.4 \mathrm{~m}$ wide above the base to $26 \mathrm{~m}$ under the saddles with a constant $18.4 \mathrm{~m}$ between internal faces and wall thickness correspondingly reducing from $3 \mathrm{~m}$ at the base. ANSYS SOLID45 elements are used to represent this, assuming full fixity at the caisson foundation levels, with saddles modeled by solid steel elements.

Main span main cables comprise 14948 galvanized $5 \mathrm{~mm}$ wires, whereas the shorter Hessle side span uses an extra 800 wire strands that are anchored at the Hessle tower saddle. Hence main cable diameters are about $0.70 \mathrm{~m}$ for the main span and Barton side span and $0.71 \mathrm{~m}$ for Hessle side span. These cables are modeled using ANSYS BEAM4 elements, with translational fixity at anchorages and saddles and sliding over saddles not allowed.

Steel inclined hangers $(8 \mathrm{~cm}$ diameter) are modeled using single LINK3 elements, and as such are pinned at each end since they offer no bending resistance in respect of global performance.

\subsection{Geometric stiffness and cable tension}

With direct access to stiffness matrices e.g. via the FE software source code, the geometric component resulting from the cable tension can be inserted directly, and static and dynamic analyses run in a single step. However, with ANSYS, dynamic analysis of a tension structure such as a suspension bridge involves a prior static analysis to identify a dead load state with equilibrium of gravity and cable axial forces. These axial forces are locked into the global stiffness matrix in subsequent analyses for dynamic and static response.

In this first step the initial strains estimated from a parabolic catenary approximation with assumed dead and live load are converted directly to tensions that imperfectly balance gravity forces that are simultaneously applied. The imperfect initial strain estimates may result in configuration (deformed state) too far from both the design condition and a few manual iterations are required. To account for varying total axial load in the main cables these were divided into six region different initial strains. For Humber the final (best) error was about $1 \mathrm{~m}$ from the configuration defined in the drawings, a value that has negligible effect on either dynamic or static behavior.

\subsection{Movement joints}

Supports and expansion joints have a major role in the bridge behavior, an effect observed in other long pan bridges (Fujino \& Siringoringo 2013). Figure 4 shows the general arrangement at a tower and the physical realization in 2013. Note that the crossbeam of one of the A-frames had collapsed onto the concrete plinth due to internal wear and at the time of writing, A-frame rockers are being replaced using two pendel bearings and a wind shoe (Hornby et al. 2012). DEMAG roller bearings provide roadway continuity between the separate spans, accommodating the horizontal movements.
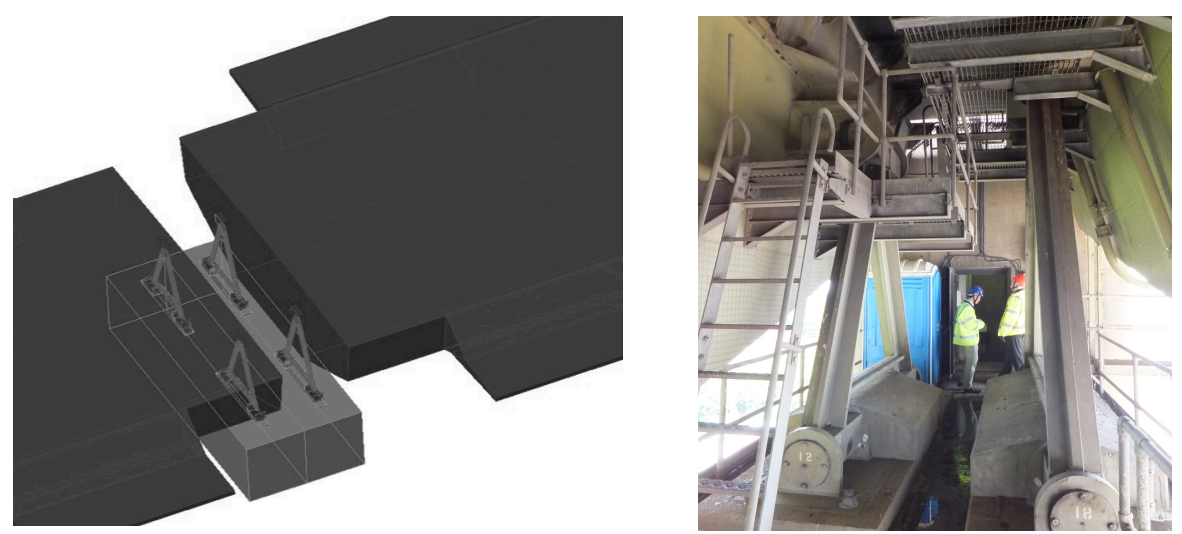

Figure 4: A-frame bearings: Left. Conceptualization of arrangement at Hessle tower with bearing pairs connected (left) to main span and (right) to Hessle side span. Right: view of A-frames at west side of Hessle tower. 
In theory bearings provide only (low) friction but in practice they provide resistance (stiffness), whose effect was studied by changing the hinges progressively from pinned to fixed via a variable stiffness. This produced significant changes in properties (principally natural frequency) for some modes in the modeling, confirming the (first) anti-symmetric mode switching observed in the original SAPIV modeling.

\section{Operational modal analysis for model calibration}

The traditional basis for calibration and adjustment of a FEM is usually an ambient vibration survey followed by operational modal analysis (OMA). The most recent exercise (2008) provided a comprehensive set of mode shapes and frequencies for vertical, lateral and torsional. Results from the 1985 exercise could not be used as they were not available in digital form, mode shapes were at a far lower resolution and crude (by 21 st century standards) OMA procedures were used. The main disadvantage of the crude 1985 OMA is that it produced positively biased damping estimates, but with smaller non-systematic errors in frequencies and mode shapes.

The 33 sets of one hour recordings from 30 channels of acceleration signals were analysed using a variety of OMA techniques including frequency domain decomposition, stochastic subspace identification and eigensystem realization algorithm (ERA). ERA as deployed in in-house software provided for normalization of cross-spectra in frequency domain that allowed gluing of mode shape pieces to produce the best set of modes, examples of which are shown in Figures 5-7.

Figures 5-7 present example comparisons of mode shapes from FEM and OMA. In each plot the dots represent the measured modal ordinates, the curved solid lines the analytical mode shapes and the straight lines the undeformed deck profile. The scatter in points for the lateral and torsional modes reflect the difficulties in OMA at very low frequencies and with modes occurring at extremely close frequencies: the first vertical torsional mode is separated from a vertical mode by as little as $0.003 \mathrm{~Hz}$. The mode shapes shown do not take advantage of summing and differencing of signals from either side of the deck, a process that greatly reduces the scatter in modal ordinates.
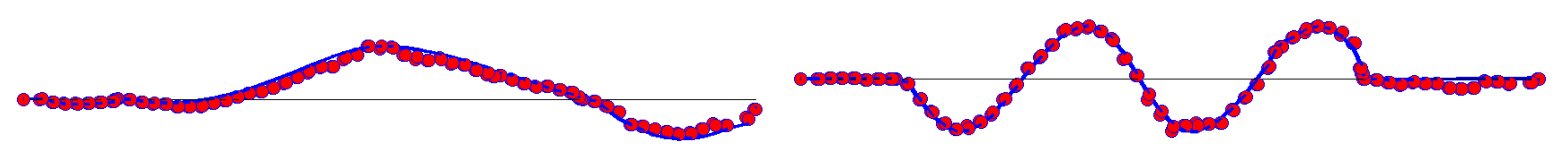

FEM $0.118 \mathrm{~Hz}$, OMA $0.117 \mathrm{~Hz}$

FEM $0.251 \mathrm{~Hz}$, OMA $0.240 \mathrm{~Hz}$

Figure 5: Example vertical modes from finite element model (FEM) and operational modal analysis (OMA), viewed from the west.

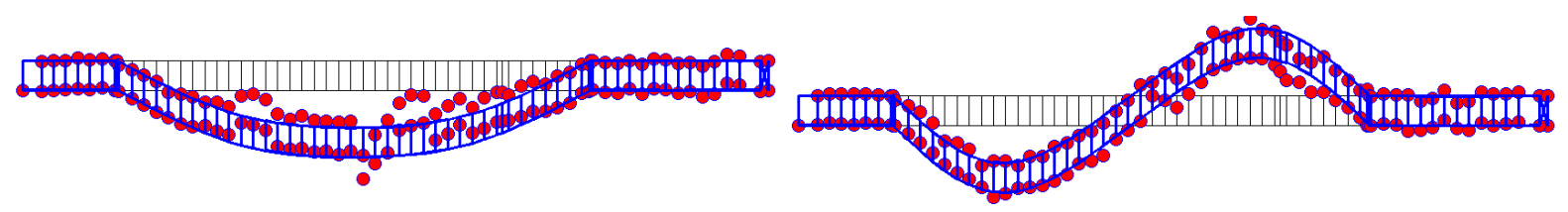

FEM $0.0522 \mathrm{~Hz}$, OMA $0.056 \mathrm{~Hz}$

FEM $0.111 \mathrm{~Hz}$, OMA $0.141 \mathrm{~Hz}$

Figure 6: Example lateral modes from FEM and OMA, viewed from above.

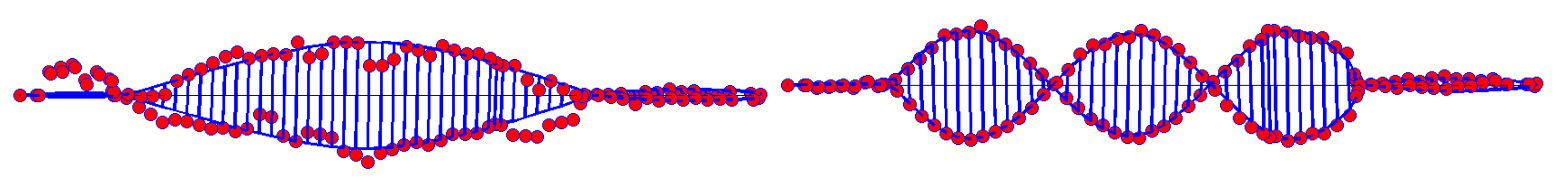

FEM $0.303 \mathrm{~Hz}$, OMA $0.311 \mathrm{~Hz}$

FEM $0.646 \mathrm{~Hz}$, OMA $0.650 \mathrm{~Hz}$

Figure 7: Example torsional modes from FEM and OMA, viewed from the west.

The systematic approach to comparing mode shapes uses the modal assurance criterion (MAC) and the more visual Frequency-MAC or 'FMAC' (Fotsch and Ewins, 2000). MAC is a simple correlation 
coefficient between corresponding modal ordinates for experimental and analytical modes such that identical modes have $\mathrm{MAC}=1$, while $\mathrm{MAC}$ values close to unity strongly indicate that modes correspond. FMAC takes all combinations of analytical and experimental mode and plots their two frequencies against each other as markers of size and color or shade that indicates the value of the corresponding MAC.

Hence in Figure 8 FEM frequencies are on the horizontal axis, OMA values on the vertical axis and quality of match is shown as markers whose colour and size increase with MAC. There are many vertical modes with similar shapes (large, dark markers) and frequencies (markers close to the $45^{\circ}$ line) up to at least $2 \mathrm{~Hz}$. However for lateral modes the FEM tends to underestimate mode frequencies and to provide relatively few good mode shape matches above $0.5 \mathrm{~Hz}$.

While the set of experimental modes identified depends on the parameters used in the identification process and the judgment of the analyst, the final OMA set as reported by (Brownjohn et al., 2010) reflects modes that recurred with strong confidence indicators. Likewise the final FEM was the result of several stages of analysis with successive adjustments to parameters having the aim of converging on the best OMA results. Stages of the manual updating involved adjusting factors such as bearing fixity (modeled as stiffness varying from zero to infinity), cable tension and deck girder detail.
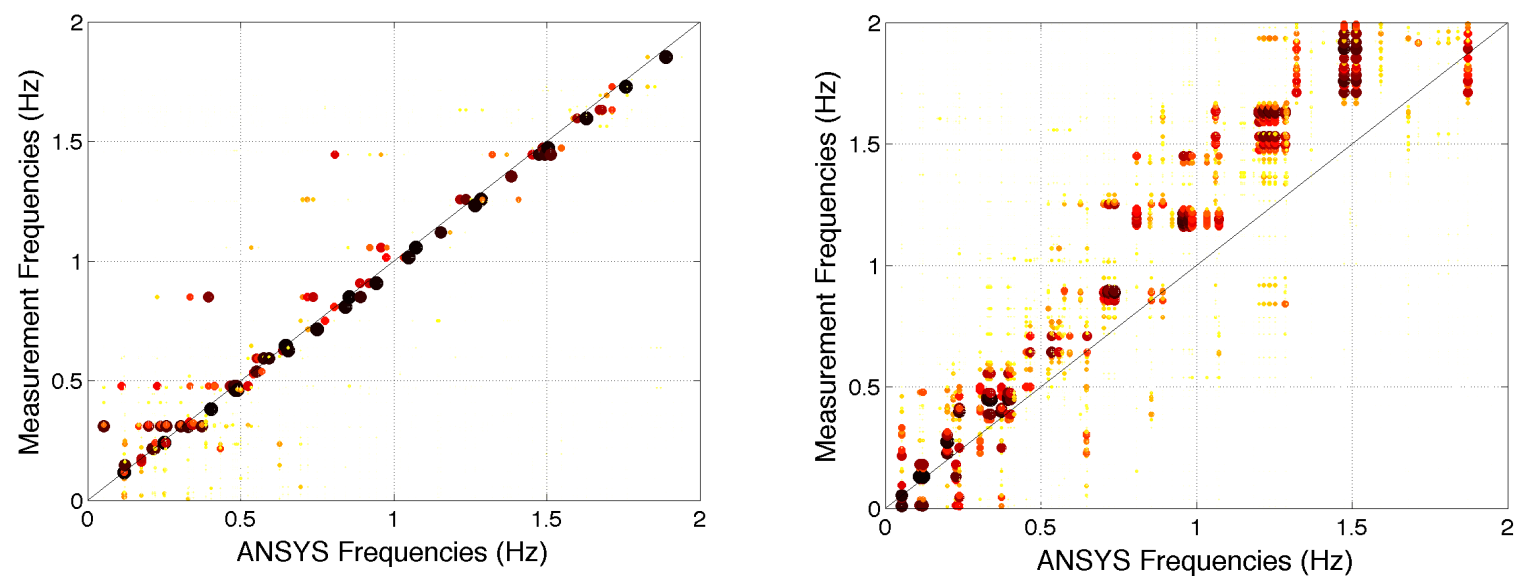

Figure 8: FMAC comparison of (left) vertical and (right) lateral mode frequencies from FEM and OMA.

\section{Comparing predicted and observed quasi-static deformations under operational loads}

The FEM variant providing the best match of mode shapes with OMA results, reported in the previous section, was further checked in terms of ability to reproduce observed static performance, for example the movements at the A-frame bearings. Observations (Brownjohn et al. 2014) have shown that the large cumulative horizontal girder movement at the A-frames is a combination of dynamic and quasi-static motion due to wind and effects of heavy goods vehicles. SHM data has shown that vertical and lateral movements are both accompanied by horizontal movement at the ends of the main span. The wind and traffic effects on bearing movement are a result of the three-dimensional (3D) deformations due to a single action and which can be understood through simulation with the FEM.

Technology for simultaneous 3D measurement of deformation at all points on a bridge is currently not available in a practical form, although deformations can be sampled with different degrees of spatial and temporal resolution and accuracy (Brownjohn et al., 2015). For example a robotic total station can track several dozen markers, but not fast enough to capture quasi-static effects of a heavy vehicle, while one GPS receiver 3D movement with adequate time resolution but for a single point. Technologies based around optics, radar and lasers are progressing but as yet do not provide a comprehensive and cost-effective solution. Hence the FEM validation through static data is based on the (spatially) sampled GPS and extensometer data, and the double-validated FEM can be used to extrapolate to the whole bridge.

Effects of individual moving vehicles are first considered because the principle of the influence line allows global deformations deformations due to point loads to be observed. 


\subsection{Vehicle Effects}

A vehicle passing over the bridge causes downward (negative) deflection at its current location, with corresponding vertical movement in adjacent spans due to the cable continuity and flexible towers. In addition, as revealed by the FEM and corroborated by the SHM system, the bridge configuration is such that significant longitudinal movements accompany the vertical deformation, plus there is a small component of lateral movement and rotation due to the offset from bridge centreline. Humber Bridge occasionally carries extreme heavy goods vehicles (HGVs) of around 100 tonnes (0.98 MN) that provide strong signals compared to effects of wind and passenger cars, making it possible to observe these time and space varying quasi-static deformations with a relatively high signal to noise ratio.

Humber Bridge has a weigh in motion (WIM) system operated independently, with heavy goods vehicles (HGVs) weight and timing data available on request. HGVs travel across the bridge under varied traffic and weather conditions, so that the deformations observed for similar weight vehicles will vary.

\subsubsection{Simulated vertical deformations}

Because bridge configuration (shape) changes due to a moving vehicle are complex, two different approaches were used to simulate the moving load using the FEM. In the first approach the force was applied to represent the vehicle moving from Hessle to Barton (north to south) on the nearside east lane in 490 steps along the bridge length, noting the midspan deformation. In the second approach the force was applied as a point load at the centre of the mid span, noting the vertical displacement as a function of position along the bridge. According to Betti's theorem and the concept of an influence line, results from these two methods should be same, as shown in Figure 9 (left). However to be completely convincing as well as to provide animation of a complete set of deformation and internal forces, the single moving force simulation was used to illustrate the complete set of deformations in all axes throughout the deck during vehicle traverse. In fact the single force was realized a set of wheel loads to avoid extreme local deformation and stresses and the two lines are deliberately separated to show equivalence.

\subsubsection{Comparison of measured and simulated vehicle-induced vertical deformations}

For clearest observation of HGV-induced deformations, data on a calm day are needed. Hence vertical displacement from east GPS receiver on 29/1/2012 was used to verify the procedure. Figure 9 (right) shows stages in processing the raw GPS data. First the linear trend is removed from the raw GPS data (thinnest line), next a low pass filter was applied to remove vertical vibrations in the lowest modes. Finally a high pass filter with an extremely low cut off frequency $(0.0006 \mathrm{~Hz})$ was used to eliminate effects of quasi-static external actions such as wind and temperature, the final result is the thick line. The two traces of Figure 9 (left and right) do not perfectly overlay due to the varying vehicle speed. 

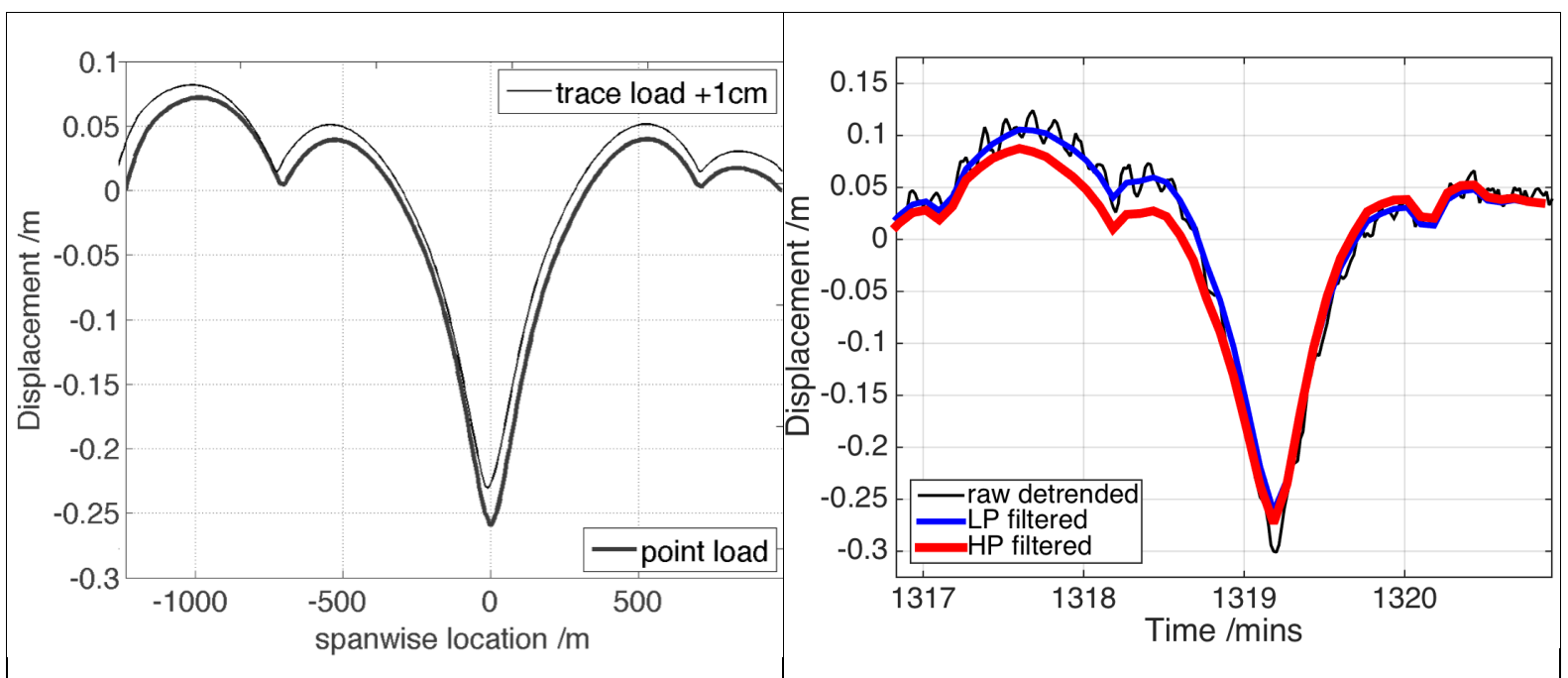

Figure 9: Left, vertical displacement of bridge main-span from FEM. Trace load is midspan deformation due to moving load, point load is global deformation due to point load at midspan. Right, raw (detrended GPS), lowpass filtered and then high-pass filtered vertical displacement for $100 \mathrm{kN}$ vehicle.

\subsubsection{Rotation about longitudinal axis measured and simulated}

The vehicle path in the nearside (most westerly) lane results in a rotation about the bridge longitudinal axis, illustrated in Figure 10. The difference between east and west position for maximum deflection is $0.034 \mathrm{~m}$ and the agreement between measurement and simulation is a good reflection of the RTK GPS capability, reported as $0.035 \mathrm{~m}$ accuracy for three standard deviations (Nickitopoulou et al. 2006).

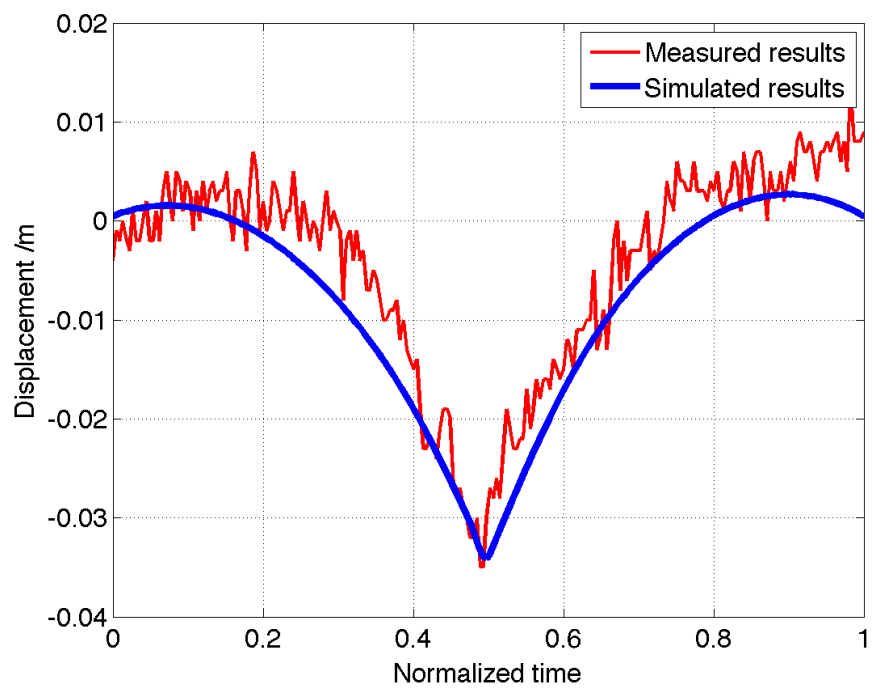

Figure 10: Comparison between simulated and measured vertical displacement differences between east and west GPS sensor position at midspan.

\subsubsection{Longitudinal displacement at bearings}

Figure 11 compares simulated movement at Hessle bearing with GPS data for a 98 tonne northbound HGV on 26/4/2012. Both simulation and observation show that the deck shifts towards the tower closer to the vehicle, then moves back to neutral and finally towards the opposite tower as the vehicle crosses. Where extension and GPS data are available simultaneously they confirm the commonality shown in the simulations. Maximum Hessle and Barton simulated bearing movements are $55 \mathrm{~mm}$ and $59 \mathrm{~mm}$ respectively, minima are $49 \mathrm{~mm}$ and $44 \mathrm{~mm}$. 

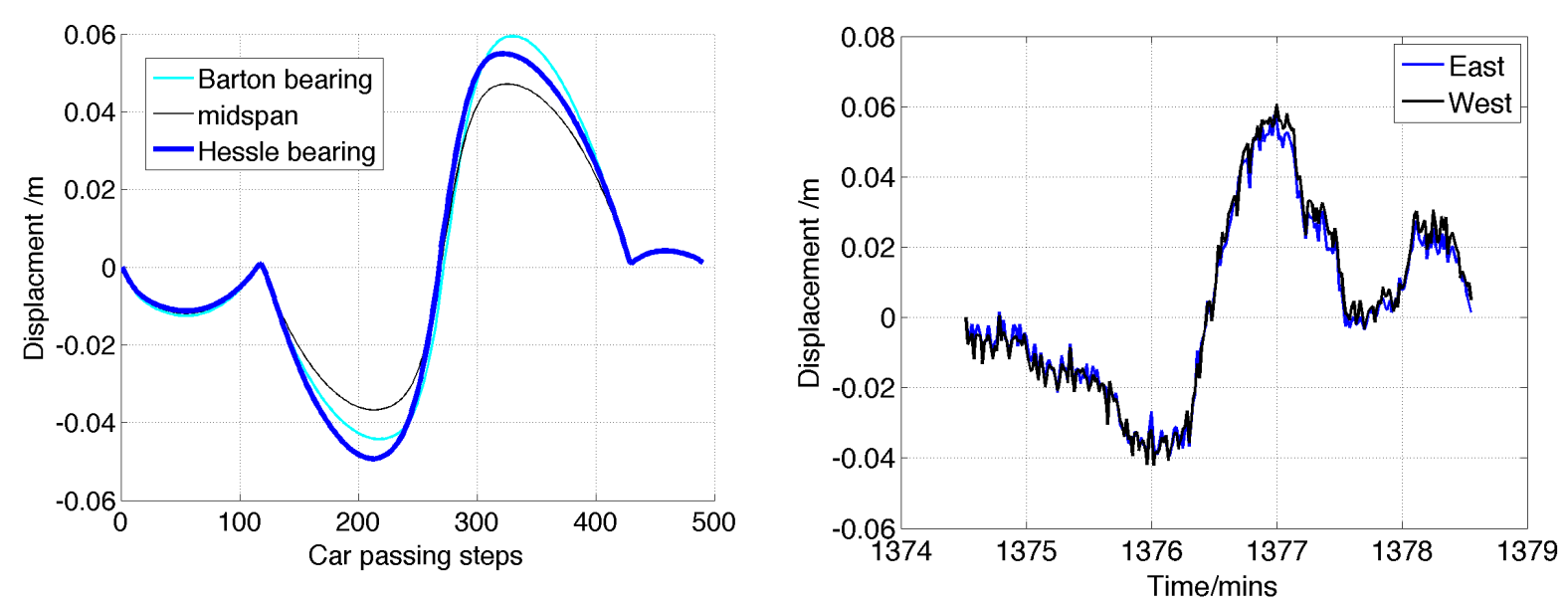

Figure 11: Comparison between simulated and measured longitudinal (northerly) displacement. Left, simulated at three points on main span and right, measured by GPS for northbound 98 tonne vehicle

To demonstrate the extrapolation capability of the FEM, the entire vehicle transit was animated to visualise deformations and stresses due to heavy vehicle transit. For example Figure 12 shows first principal stresses due to a hypothetical 170 tonne vehicle close to the Barton tower. Tension is positive, and close inspection of the area around the A-frame rocker connection to the deck shows expected stress concentration. Vehicles of such size are extremely rare; one was recorded crossing the bridge during the 1990 monitoring (Brownjohn et al., 1994).
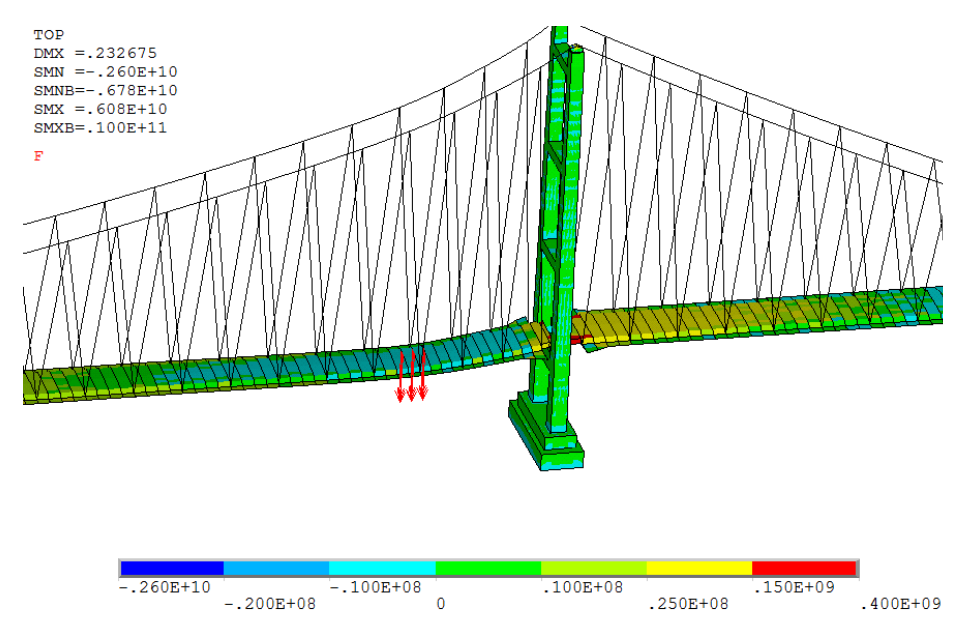

Figure 12: Stress distribution with 170 tonne vehicle close to Barton tower.

\subsection{Wind effects}

Wind is a critical load condition for a long span bridge due to the uncertain aerodynamic and aeroelastic effects partially explored during the design process via wind tunnel testing. For Humber vertical deformatio (both static and dynamic) in wind is found by observation to be significant only in the strongest winds whereas both quasi-static and dynamic lateral deformation have been signficant factors driving bearing wear due to the kinematic link with longitudinal bearing movement. Winddriven lateral displacement is also more obvious in monitoring data partly because traffic and temperature do not affect it.

\subsubsection{Measured wind effects}

Several interesting effects of wind loads have been observed during the monitoring, particularly during extreme conditions. Figure 13 shows measurements of lateral and longitudinal displacement during a hurricane force wind in January 2013 with instantaneous wind speeds reaching $39 \mathrm{~m} / \mathrm{sec}$ at a compass bearing of $255^{\circ}$ i.e. a little south of due west ( 30 minute mean speed was $26 \mathrm{~m} / \mathrm{sec}$ ). The 
strong lateral motion (GPS E) is reflected almost exactly in the differential movement of the two bearings and the ratio of lateral displacement to differential bearing longitudinal motion is approximately 30:1. The midspan GPS and bearing extension measurements show that the main span moves bodily to the north along with the lateral drift.
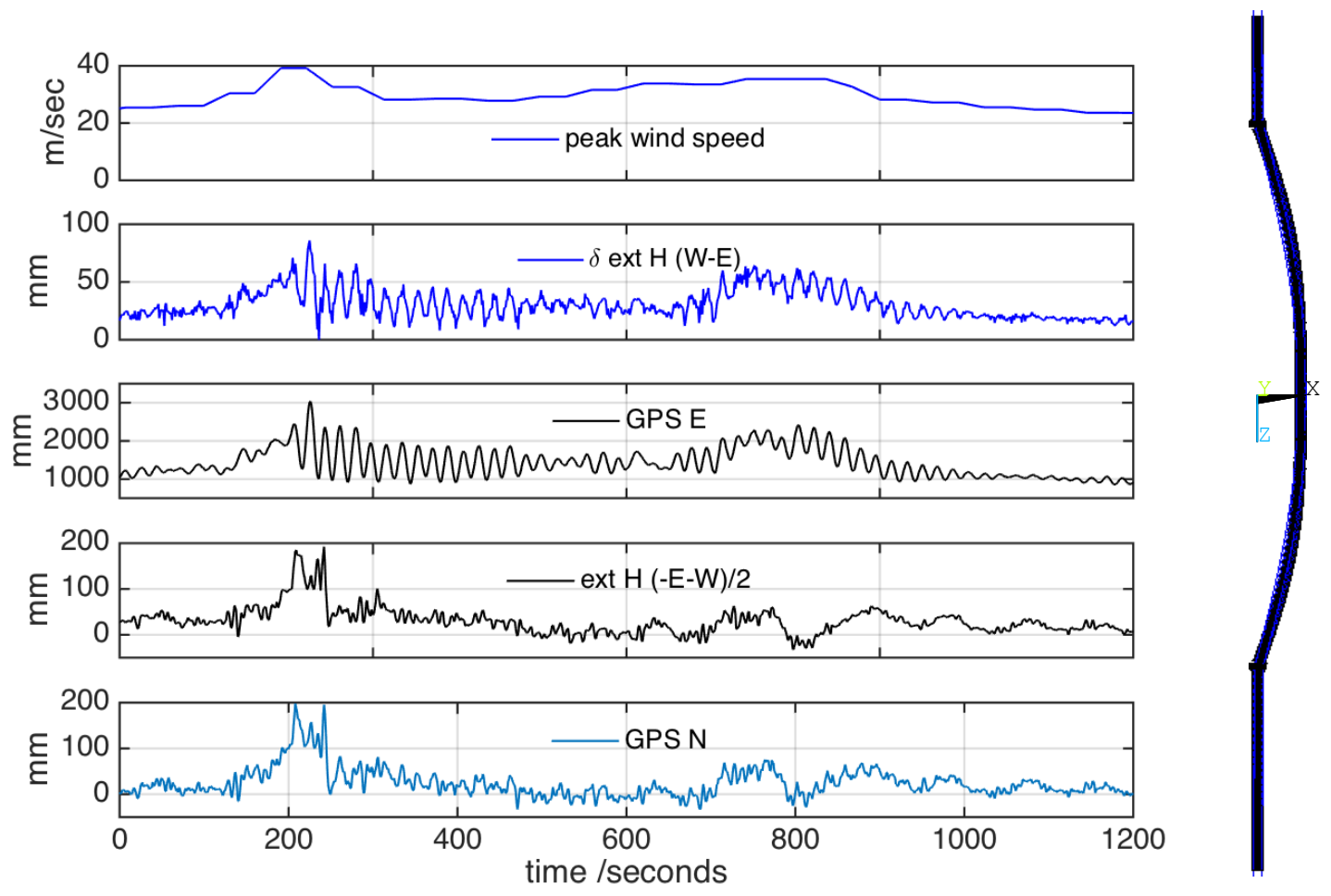

Figure 13: Wind and horizontal plane man span movements due to hurricane force wind (30/1/2013). Top to bottom: peak gust;

difference of east and west extensions at Hessle bearing; midspan GPS eastings (E) (similar trends in the two plots);

average northerly movement at Hessle bearing; midspan GPS northings (N) (similar trends in the two plots). GPS data are with respect to datum for neutral conditions. Inset (right) shows the FEM first lateral mode shape.

\subsubsection{Simulated wind responses}

Simulating wind effects is complicated by the unknown distribution of wind forces along the bridge axis and simultaneous effects on rotation about the bridge axis. The original wind tunnel investigation (Walshe \& Cowdrey 1972) provided drag coefficient $C_{D}=0.078$ for $28.5 \mathrm{~m}$ reference width and showed this to be a maximum value, at zero angle of attack. Hence a total lateral force of $100 \mathrm{kN}$ (45 $\mathrm{N} / \mathrm{m}$ ) along the length of the bridge is a reasonable representation of a uniform $5.64 \mathrm{~m} / \mathrm{sec}$ wind.

Figure 14 shows the observed and simulated effects of 'steady winds. The experimental observation is for the relationship of westerly wind component orthogonal to the deck axis and GPS eastings, both for 30 minute averages. For the full range of measured winds the zero wind datum has a $13 \mathrm{~cm}$ positive offset, while the quadratic factor $0.0019 \mathrm{sec}^{2} / \mathrm{m}$ is similar to that identified by Stephen et al., (1992). With winds limited to maximum $6 \mathrm{~m} / \mathrm{sec}$ the coefficient rises to 0.0027 . Considering only easterly winds (not shown) the coefficients are 0.0022 and 0.0037 (for winds below $6 \mathrm{~m} / \mathrm{sec}$ ), so factors such as wind angle of attack and nonlinearities in the structure or load mechanisms may influence response.

The (low wind) simulation provides a coefficient $0.004 \mathrm{sec}^{2} / \mathrm{m}$. The simulated deflections in Figure 14 are for a line along the west side of the bridge between bearings at each end, and the lateral load is applied in the easterly direction (as for a westerly wind). This is an extreme simplification as it 
assumes that wind is uniform in time and space, perfectly orthogonal to the bridge in the horizontal plane and inducing no rotation due to moment coefficient.

The longitudinal and vertical deformations on the east side are a perfect mirror image of those (shown) on the west side i.e. there is rotation about vertical axes through the towers -as observed experimentally, but no net longitudinal shift in one direction - unlike the observation. This may be due to the northerly component of the hurricane wind force. There is also rotation about the longitudinal axis but that seems to be a pure geometric effect since no aerodynamic moment has been applied.

The midspan lateral displacement is $128 \mathrm{~mm}$ for $3.5 \mathrm{~mm}$ longitudinal displacement (of one bearing), a ratio of $36: 1,18: 1$ for the differential movement, smaller than the 30:1 ratio observed at full scale during the hurricane. As already stated it is at present practically impossible to observe such a deformed shape experimentally.
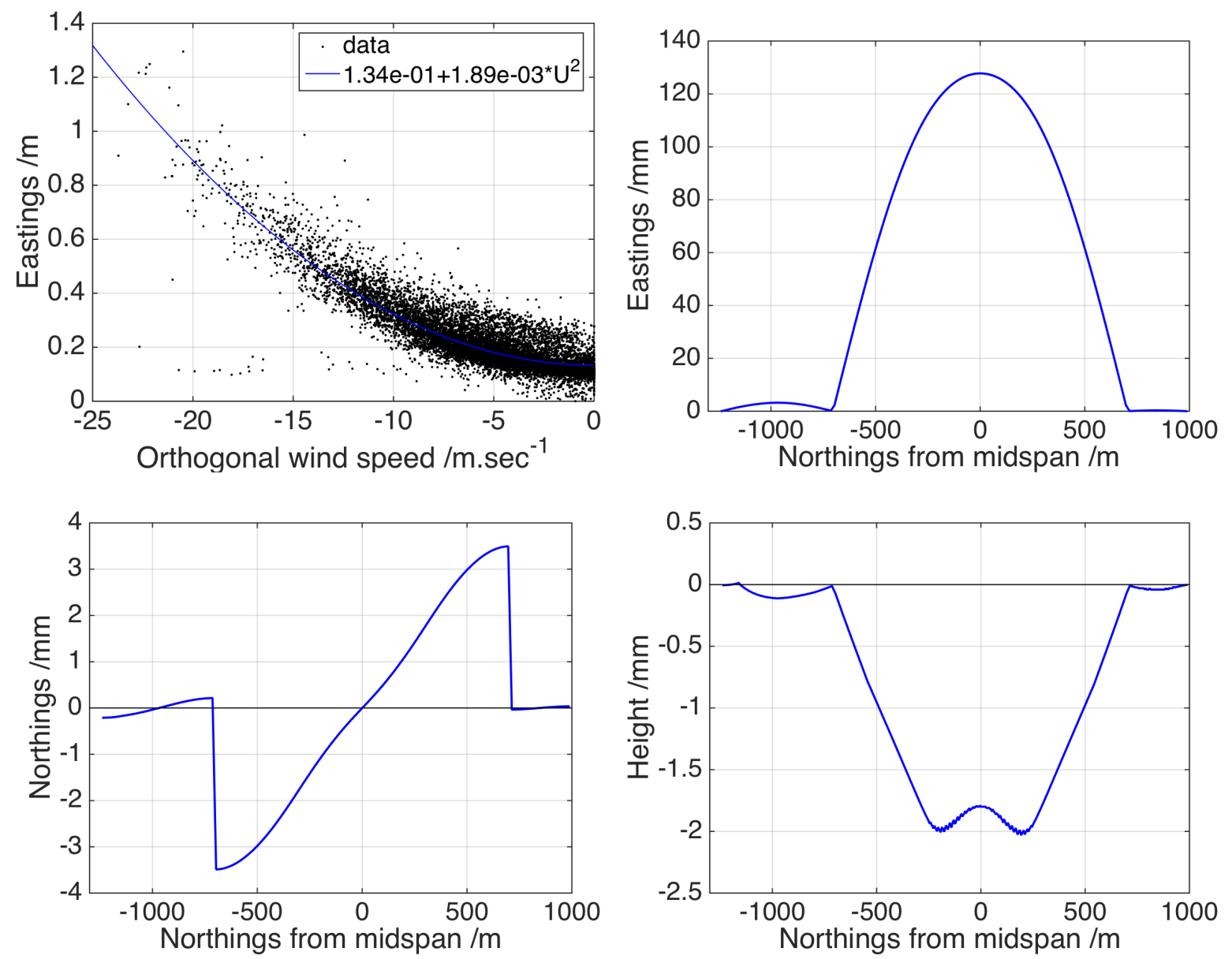

Figure 14: Clockwise from top left. Observed 30-minute averages of GPS easting and orthogonal wind speeds for westerly winds only; lateral, longitudinal and vertical deflections of west side of bridge due to pure $45 \mathrm{~N} / \mathrm{m}$ lateral load in + ve east direction.

\subsection{Temperature effects}

Effects of uniform temperature changes can easily be obtained from a single FEM analysis and checked against single point measurements with effects of wind and vehicle loads filtered out.

\subsubsection{Measured temperature effects}

Temperature effects are very clear, for example Figure 15 (left) shows the almost linear observed relationship between the temperature on the top surface inside the box and displacement in the northerly direction at both bearings (from extensometers) and midspan (from west GPS antenna), all 30-minute average values thus removing effects of vehicle-induced movement. The datum values for 
each set are arbitrary but the linear relationships for extensions are crystal clear with e.g. $9.5 \mathrm{~mm}$ Hessle bearing movement per $1^{\circ} \mathrm{C}$ increase in box temperature. There is also a weak trend for the midspan displacement. Unfortunately relationships with temperatures of air, road surface and box deck soffit are varied and nonlinear to differing extents (Figure 15, right).

Midspan vertical displacement also shows varying relationships with different temperature data, the clearest being with box soffit temperature, with $53 \mathrm{~mm}$ sag per $1^{\circ}$ increase temperature.
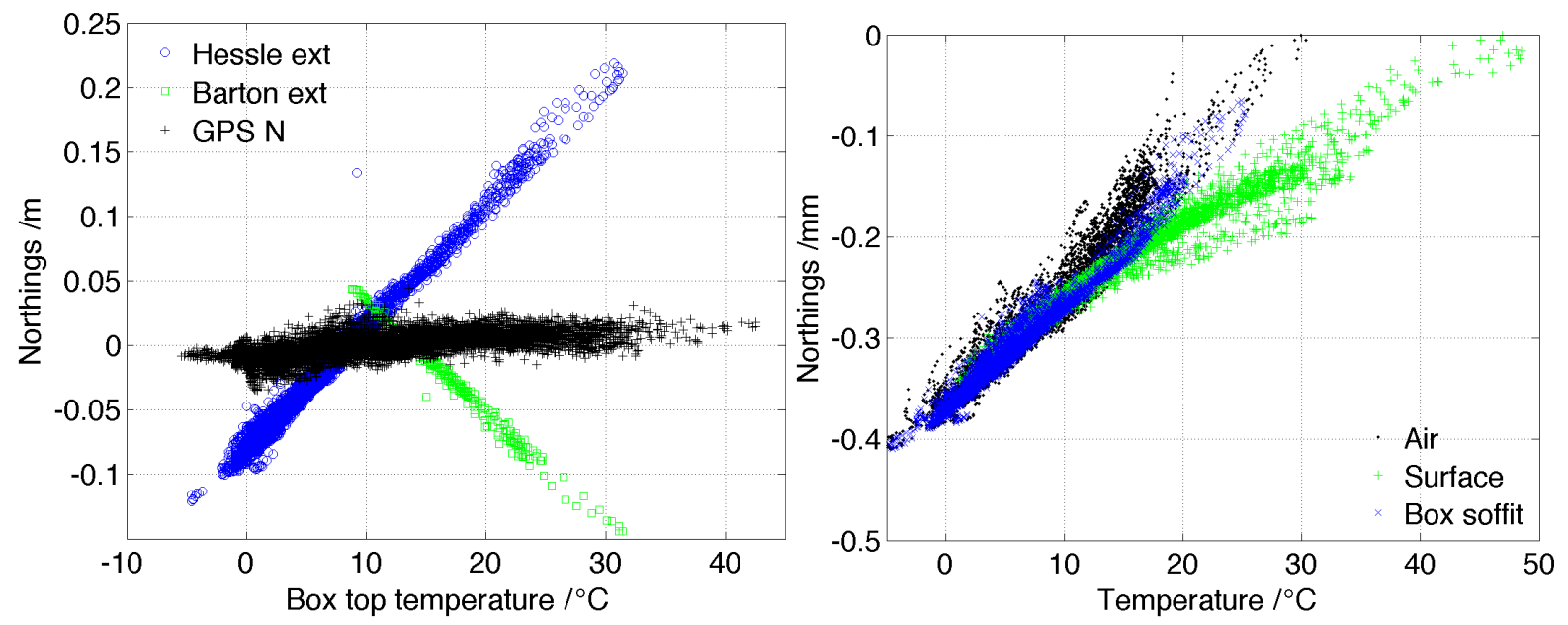

Figure 15: Temperature effects on longitudinal deformation. Left point displacements with respect to data from a single a single temperature sensor. Right Hessle extension with respect to different temperature data.

\subsubsection{Simulated results}

Effect of temperature was simulated with a uniform increase of $10^{\circ} \mathrm{C}$, the result is shown in Figure 16 with $9.5 \mathrm{~mm}$ longitudinal bearing movement and $68 \mathrm{~mm}$ midspan vertical sag per ${ }^{\circ} \mathrm{C}$. As with the wind simulation, this approach is extremely crude given that temperatures vary with location throughout the box, on the road surface and in the cables, for which data are not available. There will also be temporal variation due to varying sun azimuth and elevation and radiation intensity (Westgate at al., 2014). However the simulation matches the measurement very well for longitudinal deformation. Measuring global deformation of a long span bridge due to temperature is more feasible because of the slow changes, for example using a robotic total station (Brownjohn et al., 2015) but was not possible using the sparse instrumentation at Humber.

The simulation also shows that the box moves slightly with temperature at midspan due to the asymmetric bridge configuration, this is in line with the experimental observation in Figure 15. 

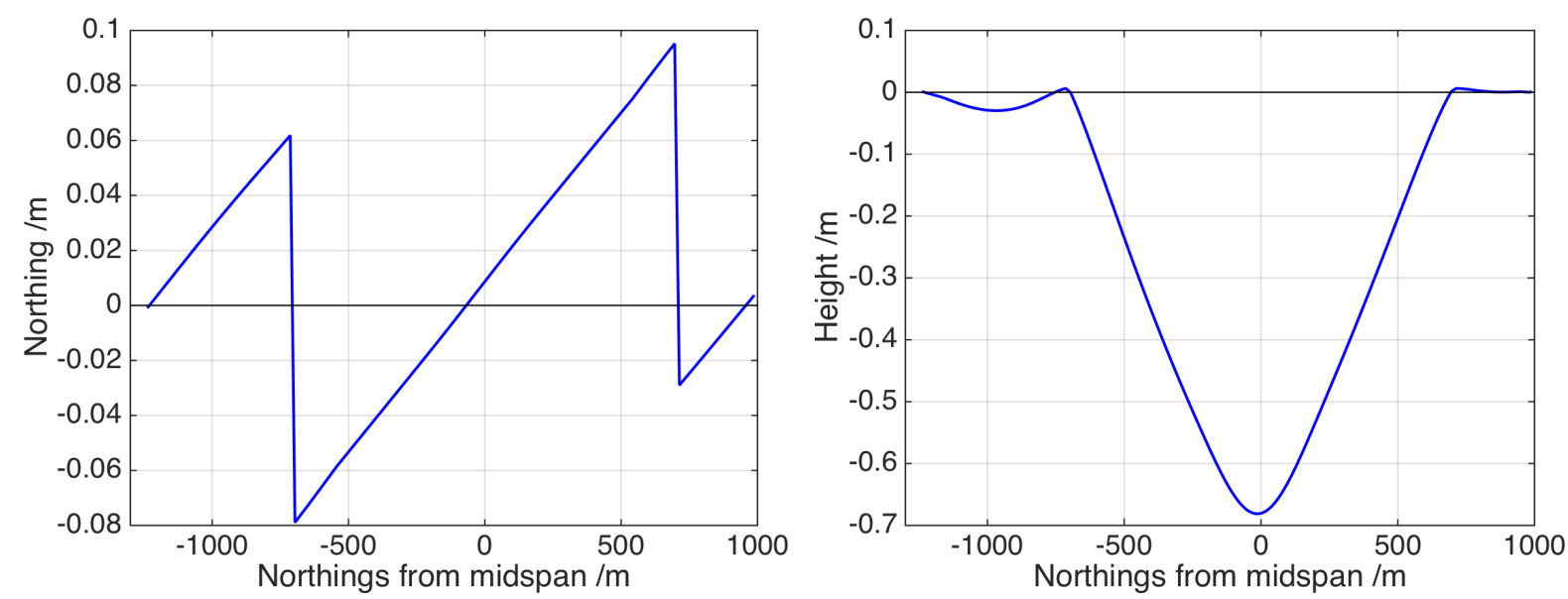

Figure 16: Vertical and longitudinal deflections due to $10^{\circ} \mathrm{C}$ temperature change throughout the structure.

\section{Performance extrapolation}

Bridge movement at supports/bearings is a critical condition. This is clear from studies such as on the Gazela Bridge (Belgrade) (Bojovi et al. 2013) where the bridge was strengthened to accommodate extreme combination of traffic and temperature effects and the Cleddau Bridge (Kromanis \& Kripakaran 2014) where transverse temperature differences resulted in serious bearing wear.

Compared to a neutral condition (ambient temperature of $10^{\circ} \mathrm{C}$, no wind, no traffic), for Humber the worst-case combinations of bearing extension (away from towers) would be at Hessle tower due to an unlikely combination of

- 100 tonne HGV halfway between Barton tower and midspan (49 mm from Figure 11)

- steady $30 \mathrm{~m} / \mathrm{sec}$ wind (100 mm from Figure 14$)$.

- low temperature, e.g. $-10^{\circ} \mathrm{C}$ (190 mm from Figure 16)

This combination is unlikely since strong winds at Humber generally go with temperate cyclonic winds and the bridge would be closed to high-sided vehicles such as HGVs with wind speeds exceeding $26 \mathrm{~m} / \mathrm{sec}$.

A more likely combination would bearing movement towards the tower at the Barton end due to

- 100 tonne HGV halfway between Hessle tower and midspan (59 mm from Figure 11)

- zero wind

- high temperature e.g. $30^{\circ} \mathrm{C}(190 \mathrm{~mm}$ from Figure 16$)$

\section{Conclusions}

A finite element model calibrated in the first instance using the results of a system identification exercise has been further checked against limited observations of static response to wind, traffic and temperature loads. This second stage of validation is rare and authors believe it is an essential step to provide credibility for simulations of extreme quasi-static behavior. The results are encouraging enough to believe in the predicted global deformations that -with present technology- could not be observed.

The whole exercise encapsulates the nature of structural identification (St-Id), which is the characterization of a structure through matching of experimental and analytical observations.

The exercise has shown that for such a landmark structure a St-Id exercise is worth the effort and that a thorough modal test combined with sparse monitoring and parallel analytical modeling is sufficient to understand and predict behavior to ranges and combinations of operational loads.

In terms of the behavior of the bridge, there are no big surprises and the simulations of static response fitted the limited observations of performance. Some differences were observed in the scale of longitudinal vehicle-induced deformation and bodily longitudinal shift observed in a strong lateral 
wind, for which a possible explanation might be the angle of the wind. In fact the least reliable and most over-simplified predictions are of wind effects.

\section{Acknowledgements}

The monitoring system and related research was funded by EPSRC (grants EP/G061130/2 and EP/F035403). Access to Humber Bridge was by kind permission of the Humber Bridge Board.

\section{References}

Abdel-Ghaffar, A.M. \& Scanlan, R.H., 1985. Ambient vibration studies of Golden Gate bridge: 1. Suspended structure, and 2. Pier tower structure. ASCE Journal of Engineering Mechanics, 111(4), $463-482$.

Ashkenazi, V. \& Roberts, G.W., 1997. Experimental monitoring of the Humber Bridge using GPS. ICE Proceedings Civil Engineering, 120, 177-182.

Bathe, K.-J., Wilson, E.L. \& Petersen, F.E., 1974. SAPIV a structural analysis program for static and dynamic response of linear structures.

Bojovi, A. Velov, N., Toljatija, P., 2013. Rehabilitation of the Gazelle road bridgein Belgrade. In The Eight International Conference "Bridges in Danube Basin", 1-38.

Brancaleoni, F. \& Diana, G., 1993. The aerodynamic design of the Messina Straits Bridge. Journal of Wind Engineering and Industrial Aerodynamics, 48(2-3), 395-409.

Brown, T.A., \& Milne, R.D. (1985). Strategies for the verification of a finite element model. In IMAC III (pp. 1031-1039). Orlando, Florida.

Brownjohn, J.M.W., Dumanoglu, A., A. Taylor, C. A., Severn, R.T., 1987. Ambient vibration measurements of the Humber Suspension Bridge and comparison with calculated characteristics. Proceedings Institution of Civil Engineers Part 2, 83, 561-600.

Brownjohn, J.M.W. ,Maglhaes, F., Caetano, E., Cunha, A., 2010. Ambient vibration re-testing and operational modal analysis of the Humber Bridge. Engineering Structures, 32(8), 2003-2018.

Brownjohn, J.M.W., Bocciolone, M., Curami, A., Falco, M., Zasso, A., 1994. Humber Bridge FullScale Measurements Campaigns 1990-1991. Journal of Wind Engineering and Industrial Aerodynamics, 52, 185-218.

Brownjohn, J.M.W., Koo, Ki-Young, Scullion, A., List, D, 2015. Operational deformations in long span bridges. Journal of Structure and Infrastructure Engineering, 11(4), 556-574

Catbas, F.N., Correa-Kijewski, T. \& Aktan, A.E., 2013. Structural Identification of Constructed Systems. Approaches, Methods and Technologies for Effective Practice of St-Id., ASCE.

Cross, E.J. Koo, K.-Y., Brownjohn, J.M.W., Worden, K., 2013. Long-term monitoring and data analysis of the Tamar Bridge. Mechanical Systems and Signal Processing, 35(1-2), 16-34.

Diana, G., Cheli, F., Zasso, A., Collina, A., Brownjohn, J.M.W. 1992. Suspension bridge parameter identification in full-scale test. Journal of Wind Engineering and Industrial Aerodynamics, 41, 165176.

Dumanoglu, A.A. \& Severn, R.T., 1987. Seismic response of modern suspension bridges to asynchronous vertical ground motion. Proceedings ICE Part 2, 83, 701-730.

Farrar, C.R. \& Lieven, N. A. J., 2007. Damage prognosis: the future of structural health monitoring. Philosophical transactions. Series A, Mathematical, physical, and engineering sciences, 365(1851), 623-32.

Friswell, M.I. \& Mottershead, J.E., 1995. Finite element model updating in structural dynamics. Springer, 1-292.

Fujino, Y. \& Siringoringo, D.M., 2013. Lessons learned from structural monitoring of long-span bridges and a tall base-isolated building. In Proceedings SHMII-6. Hong Kong. 
Hornby, S.R., Collins, J.H., Hill, P.G., Cooper, J.R., 2012. Humber Bridge A-frame refurbishment / replacement. In Proceedings of the 6th International Conference on Bridge Maintenance, Safety and Management (IABMAS). Stresa, Italy: Taylor \& Francis Group, London, 3170-3177.

Karuna, R., 2002. Structural Modelling of Suspension Bridges with Particular Reference to the Humber Bridge. PhD Thesis, Brunel University.

Koo, K.Y., de Battista, N. \& Brownjohn, J.M.W., 2011. SHM data management system using MySQL databse with MATLAB and Web interfaces. In Proceedings SHMII-5. Cancun, Mexico,

Kromanis, R. \& Kripakaran, P., 2014. Predicting thermal response of bridges using regression models derived from measurement histories. Computers \& Structures, 136, 64-77.

Kumarasena, T., Scanlan, R.H. \& Morris, G.R., 1989. Deer Isle bridge: Efficacy of stiffening systems. Journal of Structural Engineering, 115(9), 2297-2312.

Larsen, A., Esdahl, S., Andersen, J.E., Vejrum, T., 2000. Storebaelt suspension bridge - vortex shedding excitation and mitigation by guide vanes. Journal of Wind Engineering and Industrial Aerodynamics, 88(2-3), 283-296.

Littler, J.D., 1992. Ambient vibration tests on long span suspension bridges. Journal of Wind Engineering and Industrial Aerodynamics, (41-44), 1359-1370.

Littler, J.D. \& Woods, A.R., 1989. Ambient vibration tests on the Humber Bridge July 1988, BRE $\mathrm{N} 75 / 89$.

Nickitopoulou, A., Protopsalti, K. \& Stiros, S.C., 2006. Monitoring dynamic and quasi-static deformations of large flexible engineering structures with GPS: Accuracy, limitations and promises. Engineering Structures, 28, pp.1471-1482.

Stephen, G.A., Brownjohn, J.M.W. \& Taylor, C.A., 1993. Measurements of static and dynamic displacement from visual monitoring of the Humber Bridge. Engineering Structures, 15(3), 197-208.

Walshe, D.E. \& Cowdrey, C.F., 1972. A further investigation for the proposed Humber suspension bridge. Transport Research Laboratory.

Westgate, R.J., Koo, K.Y. \& Brownjohn, J.M.W., 2015. Effect of vehicular loading on suspension bridge dynamic properties. Journal of Structure and Infrastructure Engineering. 11(2), 129-144.

Westgate R, Koo K-Y, Brownjohn J. M. W. 2014, Effect of solar radiation on suspension bridge performance. ASCE Journal of Bridge Engineering (online) 10.1061/(ASCE)BE.1943-5592.0000668

Worden, K. \& Manson, G., 2007. The application of machine learning to structural health monitoring. Philosophical transactions. Series A, Mathematical, physical, and engineering sciences, 365(1851), 515-37. 